\title{
Nilai-Nilai Pendidikan Dalam Anjuran Makan Dengan Tiga Jari
}

\author{
FIRDAUS \\ Universitas Islam Riau (UIR) Pekanbaru \\ Jl. Kaharuddin Nasution, No. 113, Perhentian Marpoyan Pekanbaru 28284 \\ e-mail: firdausrida@edu.uir.ac.id
}

\begin{abstract}
One of the Sunnah of the Prophet is to eat with three fingers. What is exemplified by the Apostle has the value of education and learning. The values of education with regard to the content of the hadith content. From the analysis conducted there are some educational values that we can from what has been exemplified. First, Eat by using three fingers teach and accustom us to always be patient in every way. Second, Eating with three fingers teaches and educates us not to be greedy in seeking God's provision. Third, Eating with three fingers teaches us not to rush into action. Fourth, Eating with three fingers teaches us to be thorough in doing everything.
\end{abstract}

\section{Keywords: Sunnah, Values of Education, Eating Three Fingers}

Abstrak: Salah satu sunnah Rasulullah adalah makan dengan menggunakan tiga jari. Apa yang dicontohkan Rasul ternyata memiliki nilai -nilai pendidikan dan pembelajaran. Nilai-nilai pendidikan tersebut dengan memperhatikan kandungan dari isi hadist tersebut. Dari analisa yang dilakukan ada beberapa nilai pendidikan yang kita dapat dari apa yang telah dicontohkan tersebut. Pertama, Makan dengan menggunakan tiga jari memngajarkan dan membiasakan kita untuk selalu bersabar dalam setiap hal. Kedua, Makan dengan tiga jari mengajarkan dan mendidik kita untuk tidak berlaku tamak dalam mencari rezki Allah. Ketiga, Makan dengan tiga jari mengajarkan kepada kita untuk tidak tergesa-gesa dalam bertindak. Keempat, Makan dengan tiga jari mengajarkan kita untuk teliti dalam mengerjakan segala sesuatu.

Kata Kunci: Sunnah, Nilai-Nilai Pendidikan, Makan Tiga Jari 


\section{PENDAHULUAN}

Rasulullah saw sebagai suri tauladan telah mengajarkan kepada kita tentang adab dan kesopanan dalam menjalani kehidupan. Tujuannya agar manusia tersebut berakhlaq dan beretika dalam setiap gerak tindak perbuatannya.

Apa yang diajarkan oleh Rasulullah saw tersebut ternyata memiliki hikmah, ataupun memiliki nilai-nilai pendidikan. Yang mana nilai-nilai pendidikan tersebut sangatlah berguna untuk menanamkan akhlaq untuk menjadikan manusia yang paripurna.

Apa yang diajarkan dan dicontohkan Rasul kepada kita tentulah akan terdapat rahasia-rahasia dan hikmah dibelakangnya. Fenomena dikalangan umat islam pada saat ini mereka lebih suka dengan apa yang dicontohkan orang lain daripada apa yang telah dicontohkan oleh Rasulullah SAW.

Salah satu yang diajarkan Rasulullah kepada kita adalah adab dalam makan dan minum. Dimana untuk saat sekarang ini manusia telah meninggalkan apa yang pernah diajarkan oleh Rasulullah saw.

\section{HADITS YANG MENGANJURKAN MAKAN DENGAN TIGA JARI}

Dalam Sunan Abu Daud diriwayatkan:

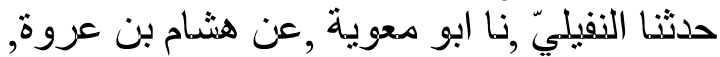

$$
\begin{aligned}
& \text { عن عبد الرحمن بن سعد, عن ابن كعب ابن ابن مالك, } \\
& \text { عن ابيه , ان النبي صلى الله عليه وسلم كان بئ بأكل }
\end{aligned}
$$

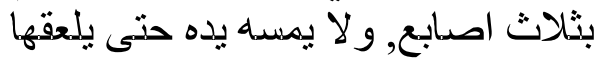

Artinya : Berbicara kepada kami Annufailiyyu, berbicara kepada kami Abu Mu'awiyah, dari Hisyam bin Urwah, dari Abdurrhman bin sa'din, dari Ibnu Ka'ab bin Malik, dari Ayahnya, "bahwasannya Rasulullah SAW makan dengan tiga jari, dan tidak mengelap tanggannya sehingga dia menjilatinya"(Sunan Abu Daud, Bab Ath 'Imah, hlm 691, no hadits 52)

Hadis senada juga diriwayatkan oleh Imam Muslim dalam Shohih muslim, diantaranya:

$$
\begin{aligned}
& \text { حدثنا ابو بكر بن ابي شيية وز هيز بن حزب و }
\end{aligned}
$$

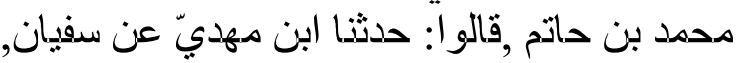

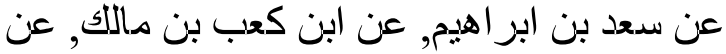

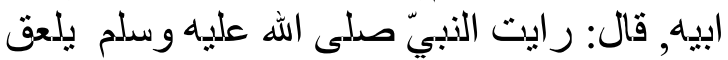

$$
\begin{aligned}
& \text { اصابعه الثلاث دن الطعام, ولم بذكر ابن حاتم : }
\end{aligned}
$$

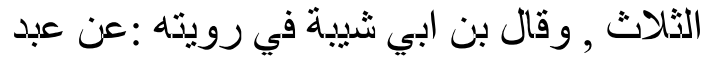

$$
\begin{aligned}
& \text { الرحمن بن كعب , عن ابيه الريه }
\end{aligned}
$$

Artinya : Berbicara kepada kami Abu Bakar ibn Abi Syaibah wa Zuhairu ibn Harbin dan Mhammad ibn Hatim, Mereka berkata: Berbicara kepada kami Ibnu Mahdiyyu dari Sufian, dari Sa'di ibn Ibrahim, dari Ka'ab ibn Malik, dari Ayahnya, Berkata : "Saya melihat Nabi Muhammad SAW menjilati jari-jarinya tiga kali dari makanannya" dan Ibn Hatim tidak menyebutkan tiga kali, dan Berkata ibn Abi Syaibah dalam riwayatnya : dari "Abdirrahman bin Ka'ab, dari Ayahnya. (HR Muslim, Bab Asyribah, hlm 976 hadist no 131).

Hadist ini juga diriwayatkan melalui jalur yang lain, yaitu :

$$
\begin{aligned}
& \text { حدثنا يحيى بن يحيى, اخبزنا ابو دعوية عن هثام }
\end{aligned}
$$

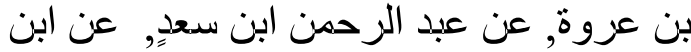

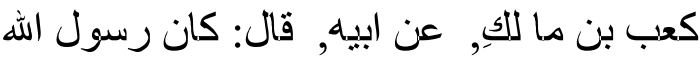

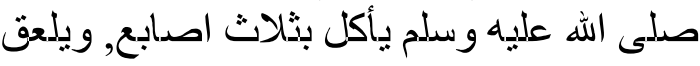

$$
\begin{aligned}
& \text { يده قبل ان يمسحها }
\end{aligned}
$$

Artinya : Berbicara kepada kami Yahya bin Yahya, Mengabarkan kepada kami Abu Mu'awiyah dari Hisyam bin 'Urwah, dari Abdirrahman bin Sa'din, dari ibn Ka'ab bin Malik, dari Ayahnya, berkata: "Rasulullah SAW makan dengan menggunakan tiga jari dan menjilati tangannya sebelum dia mengelapnya Dari jalur yang lain :

$$
\begin{aligned}
& \text { حدثثا محمد بن عبد الله بن ذميزر, حدثنا ابي, } \\
& \text { حدثنا هثنام عن عبد الرحمن ابن سعددٍ ان }
\end{aligned}
$$

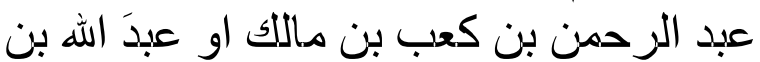

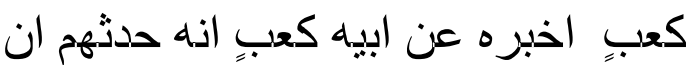

$$
\begin{aligned}
& \text { رسولَ الله صلى الله عليه وسلم كان بأكل الذه } \\
& \text { بثالغث اصدابع, فأذا فر غ لعقها }
\end{aligned}
$$


berbicara kepada kami Hisyam, dari 'Abdirrahman bin Sa'din bahwasannya 'Abdarrahman bin Ka'ab bin Malik atau 'Abdallah bin Ka'ab mengabarkan kepadanya dari Ayahnya Ka'ab,bahwasannya mereka membeicarakan "bahwa Rasulullah SAW makan dengan menggunakan tiga jari, jika telah selesai beliau menjilatinya"

Maka disini penulis akan menganalisa hadits melalui jalur Muhammad bin 'Abdullah bin Numair

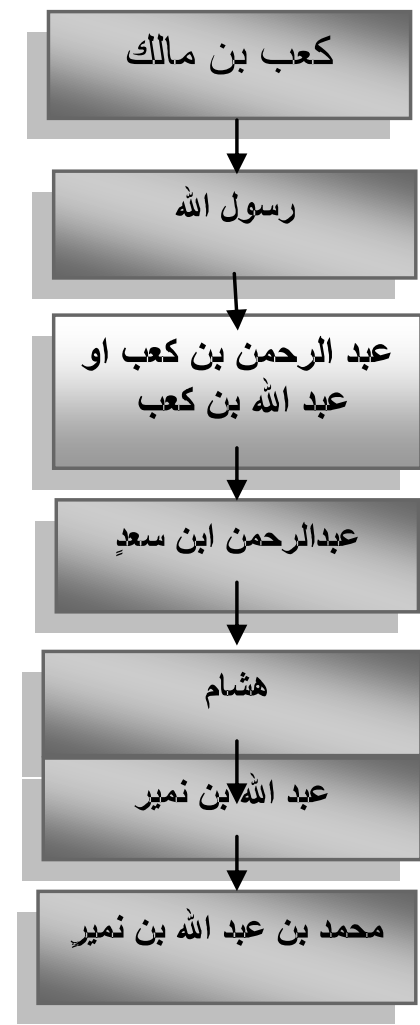

\section{ANALISA SANAD HADIST KA'AB BIN MALIK}

Ka'ab bin Malik wafat pada tahun 50 atau $51 \mathrm{H}$. Beliau dari kalangan Shohabi yang berarti beliau langsung bertemu dengan Rasulullah SAW. Adapun muridmurid beliau adalah : Jabir bin 'Abdullah, Abdullah bin Abbas, Abdullah bin Ka'ab bin Malik, Abdurrahman bin 'Abdullah bin Ka'ab bin Malik, Abdurrahman bin Ka'ab bin Malik, 'Ali bin Abi Tholhah,Umar bin al Hakim bin Sauban, Umar bin al Hakim bin Rafi, Umar bin Katsir bin Aflah, Abu Ja;far Muhammad bin Ali bin Husain, Muhammad bin Ka'ab bin Malik, Ma'bad bin Ka'ab bin Malik, Abu Amamah al bahiliyyu.

'Abdurrahman bin Ka'ab atau Abdullah bin Ka'ab

Guru-guru beliau adalah : Jabir bin 'abdillah, Salamah bin Akwa', "Abdullah bin Kaab bin Malik, Ka'ab bin Malik, Abi Qotodah al Ansoriyyi, A'isyah ra.

Adapun Murid-murid beliau adalah: Ishaq bin Abdullah bin Abi Farwah, Ishaq bin Yasar, Abu Umamah As'ad bin Sahli bin Hunaif, Sa'din bin Ibrahim bin 'Abdurrahman bin 'Auf, Sholeh bin Rustum Abu 'Amir al Khazzaz, Abdullah bin Abdurrahman bin Ka'ab bin Malik, 'Ala' bin Abdurrahman bin Ya'qub, Muhammad bin Muslim bin Syihab Az zuhriyyu, Hisyam bin Urwah, Ya'qub bin Abi Salamah Al majisun, Abdurrahman bin sa'din

Pendapat para ulama tentang 'Abdurrahman bin Ka'ab atau Abdullah bin Ka'ab adalah : beliau adalah orang yang Tsiqqoh

Abdurrahman bin Sa'din

Guru-gurunya : Abi Said Sa'din bin Malik al Khudriyyu, Sa'ad al Madani, Abdullah bin Umar bin Khattab, Ibnu Ka'ab bin Malik Abdullah atau Abdurrahman bin Ka'ab, Umar bin Abi Salamah bin Abdul Asad al Makhzumiyyu rabib Rasulullah saw, Amru bin Khuzaimah alMuzaniyyu

Murid-muridnya: Abdurrahman bin Mihram Maula Bani Hasyim, Umar bin Hamzah bin Hamzah bin Abdullah bin 'Amrul Umariyyu, Kultsum bin 'Ammar, Muhammad bin Abdurrahman bin Abi Dzikbu, Abu Aswad Muhammad bin Abdurrahman bin Nufal, Hisyam bin Urwah.

Pendapat Para Ulama tentang Abdurrahman bin Sa'din. Berkata Nasa'i dia adalah Tsiqoh, berkata ibnu Hibban dia adalah Tsiqqoh

\section{Hisyam bin Urwah (W $146 \mathrm{H}$ )}

Guru-guru beliau adalah : Bakar bi Wail, Sholeh ibnu Rabi'ah bin Hudairy al taymiyyi, Sholeh ibn Abi Sholeh as 
Samman, Abdurrahman bin Sa'din alMadaniyyi, Maula al Aswad bin Sufyan, Ubaidullah bin 'Abdurrahman, 'Umar bin Abdullah bin Umar bin Khattab

Adapun murid-muridnya adalah : Ibrahim bin Humaid Ibnu 'Abdurrahman ar-Ruasiyyu, Usamah bin Hafsa alMadaniyyu, Ismail bin ulayah, Ja'far bin 'Aun, "Abdullah bin Numair, Usman bin Farqad, "Aliy bin Masyur.

Pendapat Para ulama tentang Hisyam bin Urwah : Berkata Muhammad bin Sa'ad : dan Abu Hatim beliau adalah orang yang tsiqqoh

\section{Abdullah bin Numair (w 199H)}

Guru-guru beliau adalah : Ibrahim bin Fadli al Mahzumiyyi, Ajlah bin 'Abdullah al Kindi, Isma'il bin Abi Khalid, 'Asy as bin Sawwar, Badri bin Utsman Basyir bin Muhajir, Harits bin Hasiroh, Haritsah bin Abi Rijal, Hisyam bin Urwah,Yahya bin Said al anshori, Yazid bin Ziyad bin Abi al ja'di.

Adapun murid-murid beliau adalah : Ahmad bin Hambal, Ahmad bin Abi al Hawariyyu, Ahmad bin Abi Syu'aib al Haraniyyu, Abu Ubaidah Ahmad bin Abdullah bin Abi Syafar, Abu Masud Ahmad bin al furat ar raziyyu, Muhammad bin Abdullah bin Numair, Muhammad Umar bin Walid al Kindi, Muhammad bin Mutawakkal al Asy qolani.

Pendapat Ulama tentang Abdullah bin Numair, a Berkata 'Utsman bin Said asd daramiyyu : Tsiqqoh

Muhammad bin 'Abdillah bin Numair ( w 234 H)

Guru-guru beliau adalah : Ahmad bin Basyir al Kufiyyu, Asbath bin Muhammad al Qurasiyyu, Ishaq bin Sulaiman arRaziyyi, Ismail bin Ulayyah, Bakru bin Yunus bin Bukhair, Abu Usamah Hammad bin Usamah, Humaid bin Abdurrahman ar Ru'asiyyi, Abdullah bin Numair, Abdullah bin Yazid al Muqri'I, Ubaidullah bin Musa

Adapun murid-muridnya adalah: Bukhari, Muslim, Abu Daud, Ibn Majah Pendapat Ulama tentang Muhammad bin 'Abdillah bin Numair :
Berkata Abu Hatim, Ijliyyu, dan Ibnu Hibban : Tsiqqoh

Apabila kita perhatikan hadist diatas maka dapat kita lihat bahwa sighot yang digunakan pada hadits tersebut adalah haddasna yang berarti berbicara kepada kami. Dan juga menggunakan shighot 'an yang berarti dari. Maka shighot Haddasana dan 'An ini menunjukkan antara perawi perawi tersebut langsung bertemu. Dan berarti sighot tersebur sangatlah kuat.

Selanjutnya, jika kita melihat persambungan sanad-sanad dalam hadist ini, antara satu perawi dengan perawi lainnya saling bersambung dan bertemu satu sama lainnya. Ini dapat kita lihat dari hubungan antara murid dan guru yang saling bertemu.

Sebagai contoh: Ka'ab bin Malik bertemu dengan Rasulullah saw dikarenakan beliau dari kalangan Shohabi. Selanjutnya $\boldsymbol{K a}^{\prime} \boldsymbol{a} \boldsymbol{b}$ bin Malik memiliki murid yang bernama Abdullah bin Ka'ab. Abdullah bin $K a^{\prime} a b$ memiliki murid yang bernama Abdurrahman bin Sa'din. Dan 'Abdurrahman bin Sa'din memiliki murid yang bernama Hisyam bin 'Urwah. Hisyam bin Urwah memiliki murid yang bernama 'Abdullah bin Numair.

Inilah yang melandasi kita mengatakan bahwa sanad dari hadits diatas adalah bersambung antara satu dan lainnya.

\section{FIQH HADITS}

Secara makna hadits diatas menganjurkan kepad kita untuk makan dengan menggunakan tiga jari. Karena dalam hadits tersebut terdapat kata-kata "Rasulullah makan dengan menggunakan tiga jari".

Akan tetapi, bila kita memperhatikan hadits yang lain, dalam hadits tersebut Rasulullah menyuruh kita untuk makan dengan menggunakan tangan kanan. Menggunakan tangan berarti makan dengan lima jari yang berada ditangan kanan tersebut. 
Mengapa rasul menyuruh makan dengan menggunakan tiga jari? Disini kita haruslah mengetahui apa makanan pokok bangsa Arab pada saat itu. Bangsa Arab banyak mengkonsumsi kurma, dan roti. Yang mana kurma dan roti tersebut sangat memungkinkan untuk dikonsumsi dengan mengggunakan tiga jari. Maka bagi orang yang makanan pokoknya sulit untuk dikonsumsi dengan tiga jari, maka tidak ada dosa baginya untuk makan makanan tersebut dengan menggunakan lima jarinya.

Banyak faeadah yang didapat dari makan dengan menggunakan jari dibandingkan jika kita makan dengan menggunakan sendok. Makan dengan menggunakan jari ternyata juga lebih sehat ketimbang kita makan dengan menggunakan sendok. Hal itu disebabkan karena didalam tangan kita tersebut terdapat suatu enzim yang mana enzim tersebut dapat menekan aktifitas bakteri. Tapi tentunya saja tangan tersebut harus tetap dalam keadaan yang bersih dan higienis.

Menurut penelitian enzim tersebut hanya terdapat pada ibu jari, telunjuk dan jari tengah. Apa bila kita makan dengan menggunakan ketiga jari tersebut maka bakteri yang masuk kesistem pencernaan kita akan diikat oleh enzim tersebut sehingga aktifitas bakteri akan terhambat.

\section{PENDIDIKAN UNTUK BERSABAR}

Secara etimologis, sabar berasal dari bahasa Arab, shabara, "shbara" yang arti dasarnya menahan (al-habs), seperti habs al-hayawan (mengurung hewan), menahan diri,dan mengendalikan jiwa (Sauqi Nawawi; 2011:72)

Secara istilah, definisi sabar adalah: Menahan diri dalam melakukan sesuatu atau meninggalkan sesuatu untuk mencari keridhaan Allah.( Al Khudari; 2001:6-7) Maka dapat keta simpulkan bahwa sabar adalah menahan diri dari rasa gelisah, cemas, marah, menahan lidah, dari keluh kesah serta menahan anggota tubuh dari kekacauan.

Rasa sabar sangatlah penting untuk dilatih dalam kehidupan anak didik kita tanpa adanya rasa sabar dalam diri manusia, maka kemarahan akan sangat tidak terkendali, sehingga akan dapat merusak diri sendiri ataupun orang lain. Dalam keadaan inilah kesabaran menjadi sebuah benteng yang kokoh, yang mana potensi kemarahan dapat di bendung. Kemampuan membendung amarah seperti inilah yang membedakan antara manusia dan juga binatang.

Sabar bukanlah sesutu yang harus diterima seadanya, bahkan sabar adalah prosedur kesungguhan yang merupakan sifat Tuhan yang sangat mulia dan tinggi. Sabar adalah menahan diri dalam memikul suatu penderitaan, baik suatu urusan yang tidak diinginkan maupun dalam kehilangan sesuatu yang disenangi (Khatib Quazwain :90)

Sabar merupakan sikap jiwa yang ditampilkan dalam penerimaan sesuatu, baik berkenaan dengan penerimaan tugas dalam bentuk perintah dan larangan, maupun dalam bentuk perilakuan orang lain, serta sikap menghadapi suatu musibah.(Muslim Nurdin; 1993:239)

Begitu pentingnya sifat sabar dalam kehidupan diri manusia. Sehingga Allah swt selalu memerintahkan kepada hambanya untuk berprilaku sabar dalam kondisi dan keadaan apapun juga.

Seseorang yang didalam dirinya mempunyai sifat kesabaran yang tinggi akan dimuliakan oleh Allah swt. Pemulian allah swt karna hambanya telah melakukan suatu perintah Nya yang mana perintah tersebut tidak semua hamba dapat melakukannya. Hal ini ditegaskan oleh Allah dalam firmannya

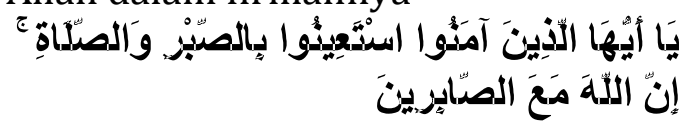

Artinya: "Hai orang-orang yang beriman, jadikanlah sabar dan shalat sebagai penolongmu, sesungguhnya Allah beserta 
orang-orang yang sabar". (QS. AlBaqarah: 153)

Inilah salah satu bentuk dari Allah memuliakan hamba-hambanya yang sabar. Allah akan selalu bersamanya, dan selalu ada untuknya. Kesabaran akan dapat mendekatkan kita kepada Rabb kita sekaligus pertolongan akan datang kepada orang-orang yang istiqomah dalam kesabarannya.

Begitu urgennya sifat kesabaran tersebut, sehingga Rasulullah saw sebagi guru kita telah mengajarkan kepada kita bagaimana memupuk rasa sabar tersebut melalui tata cara makan. Tanpa kita sadari bahwa Nabi kita mengajarkan kita berprilaku sabar melalui makan dengan menggunakan tiga jari.

Makan dengan menggunakan tiga jari mengajarkan kepada kita untuk sabar dalam setiap tindakan dan perbuatan. Walaupun kita dalam keadaan terdesak ataupun mendesak kita harus tetap dituntut untuk bersabar. Seperti halnya dengan makan tiga jari mengajarkan kepada kita walaupun kita dalam keadaan yang sangat lapar, namun kita tetap dituntut bersabar untuk memasukkan sedikit demi sedikit makanan kemulut kita.

Latihan untuk bersabar ini diajarkan Rasulullah saw melalui tata cara makan. Berarti setiap hari tanpa terasa kita selalu diajarkan oleh Rasulullah untuk berlaku sabar. Kalau setiap hari minimal kita makan tiga kali sehari, maka dalam hitungan bulan berapa kali kita diajarkan untuk bersabar. Seterusnya, berapa kali dalam setahun kita dilatih untuk bersabar melalui tata cara makan ini.

\section{MENGAJARKAN UNTUK TIDAK BERLAKU TAMAK}

Tamak terhadap harta dunia merupakan salah satu penyakit hati yang sangat membahayakan kehidupan manusia. Tamak adalah sikap rakus terhadap harta dunia tanpa melihat halal dan haramnya. Tamak bisa menyebabkan timbulnya sifat dengki, permusuhan, perbuatan keji, dusta, curang, dan bisa menjauhkan pelakunya dari ketaatan, dan lain-lain.

Ibnu al-Jauzi rahimahullah berkata, "Jika sifat rakus dibiarkan lapas kendali maka ia akan membuat seseorang dikuasai nafsu untuk sepuas-puasnya. Sifat ini menuntut terpenuhinya banyak hal yang menjerumuskan seseorang ke liang kehancuran.(Ibnu AlJauzi; 2010:25)

Sifat tamak merupakan suatu sifat yang sangat tidak disukai oleh Allah swt. untuk itu sifat ini harus benar-benar dijauhi oleh orang mukmin. Sifat tamak akan dapat menghancurkan kehidupan seseorang dan akan menghinkannya dihadapan Allah swt.

Untuk itulah Allah swt mengajarkan kepada kita untuk tidak terlalu mencintai dunia. Bibit-bibit ketamakan akan muncul dalam diri seseorang ketika orang tersebut didalam hatinya telah terlalu mencintai dunia. Sehingga apapun cara akan dia temouh dalam rangka mendapatkan dunia tersebut.

Untuk itulah Allah swt mengingatkan kepada kita melalui firmannya yang agung :

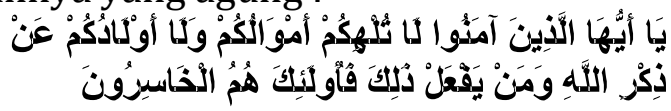

Artinya: "Hai orang-orang beriman, janganlah harta dan anak-anak kalian melalaikan kalian dari mengingat Allah. Barangsiapa yang berbuat demikian maka mereka itulah orang-orang yang merugi." (QS. Al-Munafiqun: 9)

Rasulullah mendidik kita agar terjauhi dari sifat tamak ini melalui tata cara makan .Makan dengan menggunakan tiga jari mengajarkan kepada kita untuk tidak berlaku tamak dan berlebih lebihan dalam mengambil rezeki dan nikmat Allah swt. Walaupun kita sedang membutuhkannya.

Pembiasaan ini diajarkan oleh Rasulullah dalam hal memakan makanan yang telah tersaji dihadapan kita. Artinya apabila kita mendapatkan nikmat dari 
Allah swt, maka gunakanlah nikmat tersebut sedikit demi sedikit, artinya tidak langsung menghabiskan nikmat tersebut dikarenakan sifat tamak dan rakus yang ada pada diri kita.

Tamak merupakan suatu perbuatan yang dicela dan dilarang oleh agama kita. Untuk itulah mendidik anak agar jangan berlaku tamak perlu dilakukan sedini mungkin. Nabi juga mengajarkan kita agar tidak berlaku tamak dimulai dari tata cara makan dan adab dalam memasukkan makanan kedalam mulut kita.

\section{TIDAK TERGESA-GESA DALAM BERTINDAK}

Makan dengan menggunakan tiga jari mengajarkan kita untuk tidak tergesagesa dalam mengerjakan suatu pekerjaan. Ketergesaan seseorang dalam melakukan suatu pekerjaan akan berdampak tidak baik pada hasil pekerjaan tersebut dan juga tidak baik bagi pelakunya sendiri.

Rasulullah saw bersabda:

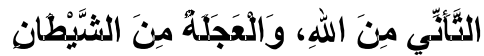

Artinya: Tidak tergesa-gesa/ketenangan datangnya dari Allâh, sedangkan tergesagesa datangnya dari setan.

Ketergesa-gesaan merupakan bisikan syetan pada hati manusia. Oleh karena itu sebisa mungkin kita menghindari sifat ketergesa-gesaan ini. Apalagi sifat tergesa-gesa dalam hal ibadah, tergesa-gesa dalam menanti pengkabulan doa dari Allah swt.

Sifat ini juga akan memberikan dampak negatif bagi manusia itu sendiri. Sifat tergesa-gesa akan mendatangkan penyesalan bagi pelakunya dikelak kemudian hari. Dikerenakan ketergesagesaan dalam bertindak akan menyebabkan hasil dari apa yang diusahakan akan kurang maksimal.

Dengan makan menggunakan tiga jari melatih kita untuk tidak tergesa-gesa dalam melakukan sesuatu dan cendrung untuk bersabar terhadap apa yang telah kita kerjakan. Kebiasaan-kebiasaan yang seperti inilah yang perlu untuk selalu kita latih. Sehingga sesuatu yang kecil yang selalu kita latih akan dapat berdampak besar dalam kehidupan kita sehari-hari nanti.

\section{MENGAJARKAN KETELITIAN}

Makan dengan menggunakan tiga jari mengajarkan kepada kita tentang ketelitian dalam mengerjakan sesuatu. Seseorang yang makan dengan menggunakan tiga jari maka cendrung akan teliti terhadap apa yang dimakannya. Dia akan memperhatikan baik-baik makanan tersebut sebelum ia memasukkannya kedalam mulut.

Ketelitian dalam mengerjakan sesuatu hal sangatlah penting. Tanpa ketelitian maka anak didik akan melakukan tugas ataupun pekerjaannya secara serabutan dan hasilnya tidak maksimal, ternyata rasulullah saw mengajarkan dan mebiasakan kita untuk berlaku teliti dari hal-hal kecil. Rasulullah mengajarkan dan mendidiknya kita untuk berlaku teliti dimulai dari makan.

\section{PENUTUP}

Sunnah-sunnah yang diajarkan oleh Rasul memberikan dampak kebaikan sekaligus memberikan pendidikan dan pengajaran kepada kita semua. Apa yang telah diajarkan oleh Rasul ternyata memiliki hikmah dibaliknya. Hikmahhikmah tersebut ternyata memiliki nilainilai pendidikan yang sangat berharga bagi kita.

Diantara hikmah yang kita dapat dari Hadits ini adalah : 1. Pendidikan untuk bersabar, 2. Mendidik kita untuk tidak berlaku tamak, 3. Tidak tergesagesa dalam bertindak, 4. Mengajarkan ketelitian.[] 


\section{DAFTAR RUJUKAN}

Al-Mazi, Jamaluddin Abi Hajjaj Yusuf. Tahdzibul Kamal fi asma'i ar rijal, Muassasah Risalah.

Asy syafi'I, Abi Fhadhil Ahmad bin 'Aly bin Hajar Syihabu ad-din 'Asolani. Tahdzibu tahdzib, Muassasah Risalah

Imam Abi Husain Muslim ibn Muslim al Qusairy Naisaburi, Jami'us as shohih.

Nawawi, Syaui Rifat. Kepribadian Qurani, Jakarta: Amzah, 2011.

Al-Khudari, Hakikat Sabar menurut al Quran, Jakarta: Darul Haq, 2001.

Quazwain, M. Khatib. Mengenal Allah: Suatu Pengajian Mengenai Ajaran Tasauf Syaikh Abdul Somad al Palimbani, Jakarta: Bulan bintang, tt.

Nurdin, Muslim. Moral dan Kondisi Islam, Bandung: Al Fabeta, 1993.

Ad-Simasyqi, Muhammad Jamaluddin al Qosimi. Bimbingan Untuk Mencapai Tingkat Mukmin, Bandung: Diponegoro, 1986.

Sabiq, Sayyid. Fiqih Sunnah, Jakarta Timur: Tinta Abadi Gemilang, 2013.

Rasyid, Sulaiman. Fiqh Islam, Jakarta: Sinar Baru Algesindo, 2012.

Rifa'I, Moh. Fiqh Islam, Semarang: Toha Putra, 1978.

I. Y Winsi K, Mu'jamul Fahros lil alfazh Hadis an Nabawi, London: Maktabah Baril, 1936. 